\title{
A Role for Synaptic Zinc in Activity-Dependent A $\beta$ Oligomer Formation and Accumulation at Excitatory Synapses
}

\author{
Atul Deshpande, ${ }^{1}$ Hideki Kawai, ${ }^{1}$ Raju Metherate, ${ }^{1}$ Charles G. Glabe, ${ }^{2,3}$ and Jorge Busciglio ${ }^{1,3}$ \\ Departments of ${ }^{1}$ Neurobiology and Behavior and ${ }^{2}$ Molecular Biology and Biochemistry, and ${ }^{3}$ Institute for Brain Aging and Dementia, University of \\ California, Irvine, Irvine, California 92697
}

Soluble amyloid $\beta$ oligomers (A $\beta 0$ s) interfere with synaptic function and bind with high affinity to synapses, but the mechanism underlying $\mathrm{A} \beta 0$ synaptic targeting is not known. Here, we show that the accumulation of synthetic or native Alzheimer's disease (AD)-brain oligomers at synapses is regulated by synaptic activity. Electrical or chemical stimulation increased A $\beta 0$ synaptic localization and enhanced oligomer formation at synaptic terminals, whereas inhibition with TTX blocked A $\beta 0$ synaptic localization and reduced $\mathrm{A} \beta 0$ synaptic load. The zinc-binding 8-OH-quinoline clioquinol markedly reduced $\mathrm{A} \beta 0$ synaptic targeting, which was also reduced in brain sections of animals deficient in the synaptic vesicle zinc transporter $\mathrm{ZnT} 3$, indicating that vesicular zinc released during neurotransmission is critical for $A \beta 0$ synaptic targeting. Oligomers were not internalized in recycled vesicles but remained at the cell surface, where they colocalized with NR2B NMDA receptor subunits. Furthermore, NMDA antagonists blocked A $\beta 0$ synaptic targeting, implicating excitatory receptor activity in oligomer formation and accumulation at synapses. In AD brains, oligomers of different size colocalized with synaptic markers in hippocampus and cortex, where oligomer synaptic accumulation correlated with synaptic loss.

\section{Introduction}

Alzheimer's disease (AD) is the major cause of dementia affecting the elderly. It is characterized by abnormal deposition of protein aggregates in the form of extracellular plaques composed of fibrillar amyloid $\beta$ protein $(\mathrm{A} \beta)$ and intracellular neurofibrillary tangles composed of hyperphosphorylated tau (Selkoe, 1991; Trojanowski and Lee, 2002; Goedert and Spillantini, 2006; Haass and Selkoe, 2007). A $\beta$ aggregation is a complex process that appears to involve more than a simple progression of soluble monomers to fibers. In fact, $A \beta$ oligomerization and fibrillization may result from independent and distinct aggregation mechanisms, such as that oligomers can be formed in an alternate assembly pathway not necessarily ending in fibril formation (Necula et al., 2007). $A \beta$ oligomerization results in multiple species including dimers, trimers, tetramers, and higher molecular weight complexes, also known as $\mathrm{A} \beta$-derived diffusible ligand (ADDL) (Lambert et al., 1998) oligomers composed of 15-20 monomers (Kayed et al., 2003), protofibrils (string of oligomers) (Nguyen and Hall, 2004), annular protofibrils (Glabe, 2004), and dodecameric oligomers (A $\beta^{\star} 56$ ) (Lesne et al., 2006). Some of these intermediate $\mathrm{A} \beta$ species, collectively designated as soluble $\mathrm{A} \beta$ oligomers (A $\beta \mathrm{O}$ ) (Glabe, 2004), bind to conformation-specific antibodies such as the polyclonal antibody A11, which recognizes

Received Dec. 16, 2008; revised Feb. 16, 2009; accepted Feb. 20, 2009.

This work was supported by grants from the Alzheimer's Association, the California Department of Public Health Alzheimer's Disease Program, and the National Institutes of Health (HD38466) to J.B. We thank Dr. William L. Klein and his research group for providing anti-ADDL antibodies and technical advice. We thank Dr. Robert Palmiter for providing ZnT3 KO mice.

Correspondence should be addressed to Jorge Busciglio, Department of Neurobiology and Behavior, University of California, Irvine, MH 2205, Irvine, CA 92697-4550. E-mail: jbuscigl@uci.edu.

DOI:10.1523/JNEUROSCI.5980-08.2009

Copyright $\odot 2009$ Society for Neuroscience $\quad$ 0270-6474/09/294004-12\$15.00/0 a generic backbone epitope common to the oligomeric state independently of the primary protein sequence (Kayed et al., 2003), and to several antibodies raised against ADDLs (Lambert et al., 2007). In addition, new evidence suggests the existence of two distinct types of soluble oligomer conformations, designated as prefibrillar oligomers (A11 positive) and fibrillar oligomers, which overlap broadly in size but are immunologically different (Kayed et al., 2007).

Recent experiments point to a major role for soluble oligomers in the disease process. Oligomers have been found in transgenic mouse models of $\mathrm{AD}$ including $3 \times \mathrm{Tg}-\mathrm{AD}$ (Billings et al., 2005; Oddo et al., 2006) and human amyloid precursor protein (hAPP) (Chang et al., 2003; Lesne et al., 2006) mice and have been detected in CSF (Kuo et al., 1996; Kayed et al., 2003; Georganopoulou et al., 2005) and brain tissue (Gong et al., 2003; Kayed et al., 2003; Lacor et al., 2004) of AD patients, where the level of soluble $\mathrm{A} \beta$ species appear to correlate with disease progression (Kuo et al., 1996; Lue et al., 1999; McLean et al., 1999; Mucke et al., 2000; Naslund et al., 2000; Moolman et al., 2004; Spires et al., 2005).

Soluble oligomers perturb synaptic function by inhibiting long-term potentiation (Lambert et al., 1998; Walsh et al., 2002; Wang et al., 2002; Cleary et al., 2005; Townsend et al., 2006) and cause learning and memory impairment in rodents (Billings et al., 2007; Holscher et al., 2007). Oligomers bind with high specificity to synaptic sites in rat hippocampal and human cortical neurons (HCNs) (Lacor et al., 2004; Deshpande et al., 2006; Lacor et al., 2007). At the synapse, oligomers appear to bind to NMDA receptors (Lacor et al., 2007) and induce NMDA receptor internalization (Snyder et al., 2005) and deregulation of NMDA signaling pathways (Roselli et al., 2005; Shankar et al., 2007). Given the emerging role of oligomers as major culprits of synaptic pa- 
thology in $\mathrm{AD}$, it is critical to understand the mechanisms by which they are targeted to synaptic sites as well as their interactions with synaptic components. To this end, we used well characterized synthetic oligomer preparations and native oligomers extracted from AD brains to investigate the role of neuronal activity in oligomer synaptic targeting. Here, we show that synaptic activity dramatically enhances both oligomer formation and localization at synaptic sites in rat and mouse hippocampal slices and primary HCNs in culture. Oligomer synaptic targeting was prevented by blockade of synaptic transmission, by the absence of zinc in synaptic vesicles, by the zinc-binding $8-\mathrm{OH}$-quinoline clioquinol, and by NMDA receptor antagonists, suggesting a role for zinc and excitatory neurotransmission in the synaptic accumulation of $\mathrm{A} \beta \mathrm{O}$. Finally, endogenous oligomers of different size were detected at synaptic terminals in AD brains, where we observed a correlation between oligomer synaptic accumulation and synaptic loss.

\section{Materials and Methods}

Preparation of hippocampal slices. Adult Sprague Dawley female rats, or 129Sv wild-type (WT) or ZnT3 ${ }^{-1-}$ mice (Cole et al., 1999), were used to prepare acute hippocampal slices. After decapitation, the brains were rapidly removed, rinsed with cold artificial CSF (ACSF), and mounted on a vibratome holder. Whole-brain coronal slices (250-300 $\mu \mathrm{m}$ thick) were sectioned with a VT1000S Vibratome (Leica Microsystems). For chemical stimulation experiments, the slices were rapidly transferred to a 24-well plate containing cold Neurobasal medium plus N2 and B27 supplements (Invitrogen) and stabilized at $37^{\circ} \mathrm{C}$ and $5 \% \mathrm{CO}-{ }_{2}$ for $30 \mathrm{~min}$ before initiation of experimental procedures. For electrical stimulation, the slices were incubated in an interface recording chamber at $34^{\circ} \mathrm{C}$ for $1 \mathrm{~h}$ before the experiment. Extra slices were maintained in ACSF at room temperature until use. To test the stability of slices, extracellular field potentials were recorded in the $\mathrm{CA} 1$ or $\mathrm{CA} 3$ regions by stimulating the Schaffer collateral or mossy fiber pathways using a concentric bipolar electrode (FHC). A glass pipette recording electrode was filled with ACSF and placed at $\sim 1 \mathrm{~mm}$ away from the stimulation site. Stimulus-evoked field potentials were amplified, filtered (CyberAmp 320 with an AI 401 headstage; Molecular Devices), and acquired using AxoGraph X (Axograph Scientific) on a Macintosh computer. To test the effect of electrical stimulation on oligomeric synaptic localization, slices were continuously stimulated at $0.1 \mathrm{~Hz}$ using a stimulus intensity that produced $\sim 90 \%$ of maximal amplitudes (monophasic 175 900 $\mu \mathrm{A}, 0.2 \mathrm{~ms}$ duration). After a baseline recording of at least $15 \mathrm{~min}$ to verify response stability, $20 \mu \mathrm{l}$ of the $\mathrm{A} \beta$ solution ( $500 \mathrm{~nm}$ final concentration) was applied directly to the slices every $20 \mathrm{~min}(60 \mu \mathrm{l}$ total $)$ at both the stimulation/ recording site and the nonstimulated contralateral hippocampus. After $1 \mathrm{~h}$ of treatment, the slices were fixed and processed for immunostaining and image analysis.

Neuronal cultures. Neuronal cultures were established from 16- to 21-week-old human fetal brain tissue specimens as described previously (Pelsman et al., 2003; Deshpande et al., 2006). The protocols for tissue procurement complied with federal and institutional guidelines. Briefly, cortical tissue samples were dissociated into a single-cell suspension by incubation with $0.25 \%$ trypsin/PBS at $37^{\circ} \mathrm{C}$ for $30 \mathrm{~min}$ and mechanically dissociated by using a fire-polished glass Pasteur pipette. Cells were plated at a density of 20,000 cells $/ \mathrm{cm}^{2}$ on $35 \mathrm{~mm}$ glass-bottom dishes or glass coverslips in $100 \mathrm{~mm}$ culture dishes. Within the first $2 \mathrm{~h}$ after plating, the medium was changed to Neurobasal plus N2 and B27 supplements (Invitrogen). Partial medium changes (50\%) were performed every $5 \mathrm{~d}$. All experiments were performed at day 21 in culture.

$A \beta$ preparations and treatment. Soluble $A \beta O$ s were prepared as described previously (Necula et al., 2007). A $\beta_{1-42}$ stock solutions ( $2 \mathrm{~mm}$ ) were obtained by dissolving the lyophilized peptide in $100 \mathrm{~mm} \mathrm{NaOH}$, followed by incubation for $10 \mathrm{~min}$ and water bath sonication for $30 \mathrm{~s}$. The oligomerization reaction was initiated by diluting the stock solution in PBS (45 $\mu \mathrm{M}$ final $\mathrm{A} \beta_{1-42}$ concentration, $\mathrm{pH}$ 7.4). Fresh $\mathrm{A} \beta$ monomeric solutions were prepared immediately before addition to the cultures, whereas oligomeric preparations were incubated for $5 \mathrm{~d}$ as described previously (Necula et al., 2007). ADDLs were prepared as described previously (Lacor et al., 2004). For most experiments, A $\beta$ Os or ADDLs were added to slices and HCNs at a final concentration of $500 \mathrm{~nm}$.

Chemical modulation of neuronal activity. Rat slices or HCNs were incubated with $500 \mathrm{~nm} \mathrm{~A} \beta \mathrm{O}$ and $100 \mu \mathrm{m}$ glutamate (adjusted at $\mathrm{pH}$ 7.2; Sigma), $20 \mathrm{~mm}$ potassium chloride (KCl), $1 \mu \mathrm{m}$ tetrodotoxin (TTX; Sigma), or $1 \mu \mathrm{M}$ clioquinol (Sigma) and fixed in $4 \%$ paraformaldehyde/ $0.12 \mathrm{M}$ sucrose in $\mathrm{PBS}$ for $30 \mathrm{~min}$ at $37^{\circ} \mathrm{C}$. Slices or cultures growing on glass coverslips were further processed for immunofluorescence.

Drugs. The following drugs were used to modulate NMDA and AMPA receptor activity: NMDA receptor antagonists 2-amino-5phosphonovaleric acid (APV; $10 \mu \mathrm{M}$; Sigma), 1-amino-3,5-dimethyladamantane (memantine, $10 \mu \mathrm{M}$; Sigma), 4-[2-[4-(cyclohexylmethyl)1-piperidinyl]-1-hydroxypropyl]phenol (ifenprodil, $5 \mu \mathrm{M}$; Sigma) and the AMPA receptor antagonist 6-cyano-7-nitroquinoxaline-2 3-dione (CNQX; $10 \mu \mathrm{M}$; Sigma).

Endocytosis of $A \beta O$ s. HCNs were simultaneously incubated with 500 $\mathrm{nm} \mathrm{A} \beta \mathrm{O}$ and either $100 \mu \mathrm{m}$ glutamate or $20 \mathrm{~mm} \mathrm{KCl}$, and $5 \mu \mathrm{M}$ AM4-64 (Biotium) for $5 \mathrm{~min}$ in Neurobasal medium. For some experiments, neurons were preincubated with $1 \mu \mathrm{M}$ TTX for 20 min before bath application of AM4-64 or AM4-64 and A $\beta$ O. Experiments were finalized by quickly washing the cultures with ice-cold HBSS and fixation as described below.

Human brain tissue and immunofluorescence procedures. The Institute for Brain Aging and Dementia Tissue Repository at the University of California-Irvine provided the human brain tissue used in this study. Tissue samples from the hippocampus and cortex of 15 neuropathologically confirmed $\mathrm{AD}$ cases and 10 nondemented individuals with no evidence of plaques or tangles were analyzed. Free-floating, paraformaldehyde-fixed, 30 - to $50-\mu \mathrm{m}$-thick serial sections from hippocampus and frontal and entorhinal cortices were used for immunofluorescence studies as described previously (Head et al., 2002). For doubleand triple-labeling experiments, the sections were incubated in primary antibodies at the indicated concentrations (see below) for $12 \mathrm{~h}$ at room temperature. Rat brain slices and HCNs were fixed in $4 \%$ paraformaldehyde $/ 0.12 \mathrm{M}$ sucrose in PBS for $30 \mathrm{~min}$ at $37^{\circ} \mathrm{C}$, permeabilized with $0.2 \%$ Triton X-100/PBS, and blocked for $2 \mathrm{~h}$ with 5\% BSA/PBS. The following primary antibodies were used: rabbit anti-oligomer A11 (1:2500) (Kayed et al., 2003); mouse anti-ADDL (1:200; clones NU-2 and NU-4) (Lambert et al., 2007); rabbit anti-ADDL M69 (1:200) (Lambert et al., 2007); rabbit anti-annular protofibrils (1:1000) (Kayed and Glabe, 2006); mouse anti-synaptophysin (1:500; Calbiochem); and mouse anti-NR2B (1:1000; Millipore). Primary antibodies were incubated overnight at $4^{\circ} \mathrm{C}$, followed by a $2 \mathrm{~h}$ incubation with fluorescent-conjugated secondary antibodies (1:200; Alexa 488 and Alexa 594; Invitrogen). The signal of oligomer conformation-dependent antibodies was amplified using the ELF kit (Invitrogen) following the manufacturer's protocol. Competition with an antigenic peptide, use of a nonimmune IgG instead of a primary antibody, or omission of a primary antibody resulted in complete elimination of specific fluorescent signals. An Axiovert 200 inverted microscope (Zeiss) was used for specimen examination and imaging. Images were captured at a final magnification of $630 \times$ and processed using AxioVision software (Zeiss).

Colocalization studies. To assess colocalization of synaptic markers, an Apotome device (Zeiss) was used for optical "Z" sectioning of multifluorescence signals. To quantify the frequency of colocalization in slice cultures, at least 20 images at $630 \times$ final magnification were captured in each predetermined region in CA1, CA3, and the dentate gyrus, respectively (see Fig. 1A). Thus, at least 60 fields were analyzed per slice. Triplicate slices were analyzed per condition in each experiment. Oligomer synaptic localization was expressed as a percentage of oligomer puncta colocalized with synaptophysin per field. To quantify the frequency of colocalization of fluorescent signals in $\mathrm{HCNs}$, at least 20 fields per coverslip in HCNs were captured and processed for image analysis. Triplicate coverslips per condition were analyzed in each experiment. To assess synaptic density and frequency of oligomer/synaptic marker colocalization in human brains, three areas were analyzed: frontal cortex, entorhinal cortex, and hippocampus. At least 10 microscopic fields were assessed 
per region. The identity of the cultures or human brain sections was coded to avoid experimental bias. We designed a module in AxioVision to isolate puncta-like objects based on the intensity, shape, and size of the objects. The threshold for object size was set at $150 \mathrm{~nm}$, whereas objects $>1000 \mathrm{~nm}$ were excluded from the analysis. Images were then processed using the colocalizer module. The overlap between presynaptic and postsynaptic fluorescent signals was used to define synaptic sites. In most cases, we observed partial overlap or colocalization of the signals, which is expected based on the apposition of presynaptic and postsynaptic structures, the diversity in the spatial orientation of the objects, and the resolution limits of the imaging system. Anti-oligomeric conformationspecific antibodies and synaptic markers (see above) were used to quantify the frequency of colocalization of both signals. To confirm the colocalization of fluorescent signals, TetraSpeck beads (TetraSpeck Fluorescent Microspheres Sampler kit; Invitrogen) were used as a positive control. Each $500 \mathrm{~nm}$ bead is labeled with four different fluorophores enabling to correct for potential plane shifts associated with each individual fluorescent filter. For image rendering, three-dimensional (3D) reconstructions of the target fields were generated and qualitatively analyzed for overlap between postsynaptic density-95 (PSD-95)-, synaptophysin-, or $\mathrm{A} \beta \mathrm{O}$-immunoreactive objects using the AxioVision Inside4D module.

Extraction of oligomers from AD brains. Cortical tissue samples from $\mathrm{AD}$ brain specimens were diced and homogenized in PBS plus $0.02 \%$ $\mathrm{NaN}_{3}, \mathrm{pH}$ 7.4, and protease inhibitors (Complete; Roche). The volume of buffer was five times greater than the mass of tissue. The samples were centrifuged at $100,000 \times g$ for $1 \mathrm{~h}$ at $4^{\circ} \mathrm{C}$. Soluble fractions positive for A11 immunoreactivity by dot blot analysis (Kayed et al., 2003) were also used for Western blot and synaptic targeting experiments. A11-negative soluble fractions from age-matched brains with no $\mathrm{AD}$ pathology were used as controls. PAGE was performed as described previously (Deshpande et al., 2008). Native gels were run in the absence of SDS and reducing agents.

Statistical analysis. All individual experiments were repeated at least three times in acute slices or dissociated cultures derived from different brain specimens. Each individual experiment was performed in triplicate. Data were analyzed by an unpaired Student's $t$ test or ANOVA followed by post hoc comparisons using Tukey's test. Results were expressed as the mean \pm SEM. Significance was assessed at $p<0.05$. All results shown correspond to individual representative experiments.

\section{Results}

\section{Synaptic activity modulates $\mathrm{A} \beta \mathrm{O}$ targeting to synaptic terminals}

Previous reports have established a high frequency of oligomer localization at synaptic sites (Lacor et al., 2004, 2007; Deshpande et al., 2006). Both $\mathrm{A} \beta \mathrm{O}$ s and ADDLs bind rapidly and with remarkable specificity to synapses in HCN cultures (Deshpande et al., 2006). Thus, the mechanism by which oligomers are targeted to synapses is a crucial step in the pathological cascade. We used acute rat hippocampal slices to assess whether synaptic activity plays a role in oligomeric synaptic targeting. Immunolabeling with anti-oligomer A11 and antisynaptophysin antibodies was used to assess the localization of oligomers to synapses under basal conditions (nonstimulated), or after chemical stimulation or inhibition of synaptic activity. An initial semiquantitative scan of brain areas including the hippocampus, entorhinal cortex, frontal cortex, and cerebellum was performed to assess the extension of oligomeric synaptic binding in rat brain slices. Higher frequency of $\mathrm{A} \beta \mathrm{O}$ synaptic localization was observed in the hippocampal formation and entorhinal and frontal cortices. We focused the quantitative analysis in three hippocampal regions localized in CA1, CA3, and the dentate gyrus, respectively (Fig. $1 A$ ). Twenty images at $630 \times$ final magnification were captured in each region. In total, 60 fields per slice were analyzed for oligomer synaptic localization. Unstimulated hippocampal slices incubated with $500 \mathrm{~nm} \mathrm{~A} \beta \mathrm{O}$ for $1 \mathrm{~h}$ showed modest synaptic localiza- tion as evidenced by image analysis and colocalization with synaptophysin (14.09 $\pm 4.17 \%$ ) (Fig. $1 B, C$ ). Simultaneous addition of $\mathrm{A} \beta \mathrm{O}$ and $\mathrm{KCl}(20 \mathrm{mM})$ or glutamate $(100 \mu \mathrm{M})$ resulted in a dramatic increase in $\mathrm{A} \beta \mathrm{O}$ synaptic localization (63.74 \pm 7.50 and $57.81 \pm 10.84 \%$, respectively) (Fig. $1 B, C$ ). Preincubation of slices with $2 \mu \mathrm{M}$ TTX for $20 \mathrm{~min}$ before the addition of $\mathrm{A} \beta \mathrm{O}$ and glutamate completely blocked the increase in $\mathrm{A} \beta \mathrm{O}$ synaptic localization $(8.96 \pm 3.40 \%)$ (Fig. $1 B, C)$. Incubation with $\mathrm{KCl}$, glutamate, or TTX had no effect on synaptic density, as determined by quantification of colocalization of presynaptic and postsynaptic markers synaptophysin and PSD-95 (data not shown), ruling out potential variations in synaptic density attributable to the drug treatments. Maximum oligomer synaptic occupancy was observed between $30 \mathrm{~min}$ and $1 \mathrm{~h}$ after oligomer addition (Deshpande et al., 2006). Longer incubation times up to $5 \mathrm{~h}$ did not significantly change the percentage of oligomer synaptic localization under basal conditions or glutamate stimulation. However, when slices were incubated for $5 \mathrm{~h}$ with glutamate and $\mathrm{A} \beta \mathrm{O}$, and TTX was added to the medium for the last $4 \mathrm{~h}$ of incubation time, there was a marked reduction in the amount of $\mathrm{A} \beta \mathrm{O}$ colocalized with synaptophysin (Fig. $1 D$ ), indicating that once $\mathrm{A} \beta \mathrm{O}$ synaptic localization reached maximum levels, it can be partially reduced by silencing neuronal activity. Comparable results were obtained using ADDL preparations (data not shown). A similar activity-dependent effect on $\mathrm{A} \beta \mathrm{O}$ synaptic targeting was observed in HCNs (supplemental Fig. 1, available at www. jneurosci.org as supplemental material), with the exception that $\mathrm{A} \beta \mathrm{O}$ synaptic localization under unstimulated conditions was higher in HCNs than in hippocampal slices, possibly because of higher antibody accessibility and/or increased spontaneous activity in dissociated cultures.

To determine whether more physiological forms of synaptic stimulation would also modulate $\mathrm{A} \beta \mathrm{O}$ synaptic targeting, we used focal electrical stimulation in CA1 and CA3 regions at the Schaffer collateral and mossy fiber pathways (see Materials and Methods for technical details). After a baseline recording of evoked field potentials, three aliquots of $20 \mu \mathrm{l}$ of $\mathrm{A} \beta \mathrm{O}$ solution (500 nM final concentration) were applied directly to the slices (one aliquot every $20 \mathrm{~min}, 60 \mu \mathrm{l}$ total) at the stimulation/recording site and also at the nonstimulated contralateral hippocampus. After $60 \mathrm{~min}$, the slices were fixed, immunostained, and processed for image analysis. There was a significant increase in oligomer synaptic targeting in the stimulated areas compared with the same areas in the unstimulated contralateral hippocampus. The increase in oligomer synaptic accumulation was completely prevented by coincubation with A11 but not by coincubation with nonimmune Ig (Fig. $1 E$ ), indicating that antibody-bound oligomers lose their ability to attach to synapses. Collectively, these results indicate that oligomer targeting and localization to synaptic terminals is regulated by synaptic activity.

\section{Synaptic targeting of $\mathrm{A} \beta \mathrm{O}$ is mediated by zinc}

One mechanism that may contribute to the increase in activitydependent oligomeric targeting to synapses is the elevated concentration of metal ions, particularly zinc, at the synaptic cleft after glutamate release (Frederickson and Bush, 2001; Mocchegiani et al., 2005; Mathie et al., 2006). $A \beta$ is a metal-binding protein with high affinity for copper and zinc (Bush et al., 1994a; Atwood et al., 2000). Zinc promotes $\mathrm{A} \beta$ oligomerization (Curtain et al., 2001) and is concentrated in synaptic vesicles at glutamatergic synapses throughout the cortex and the hippocampal formation. Zinc is released during synaptic activity, reaching extracellular concentrations close to $300 \mu \mathrm{M}$ (Frederickson and Bush, 2001). 
A

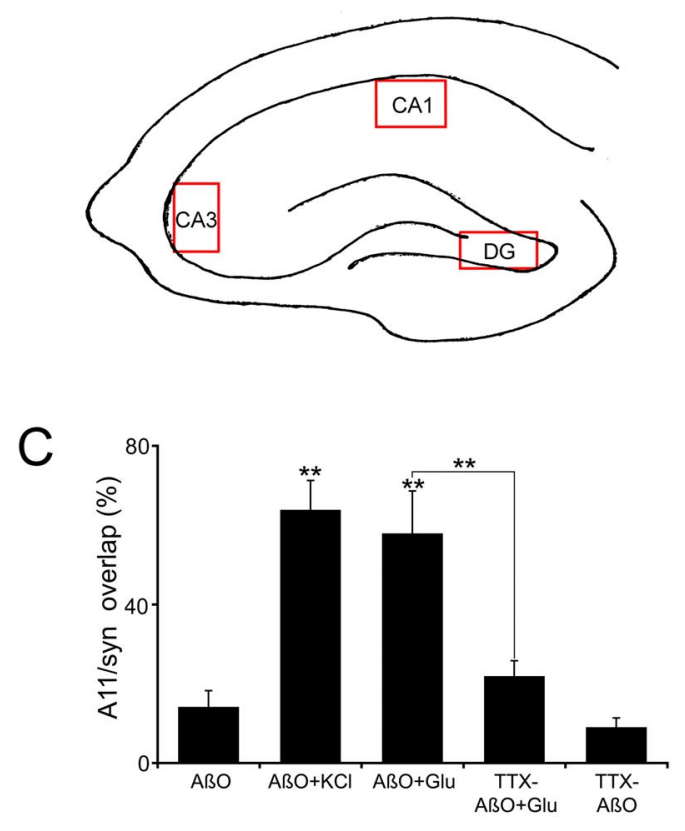

D

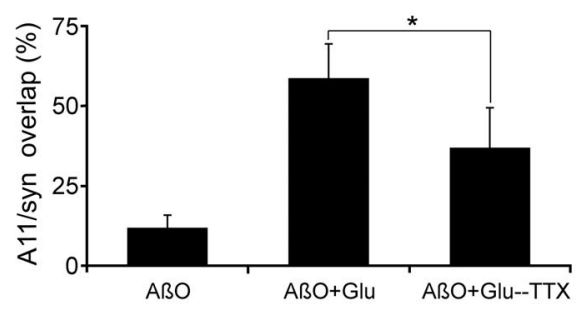

B

syn

$\mathrm{ABO}$
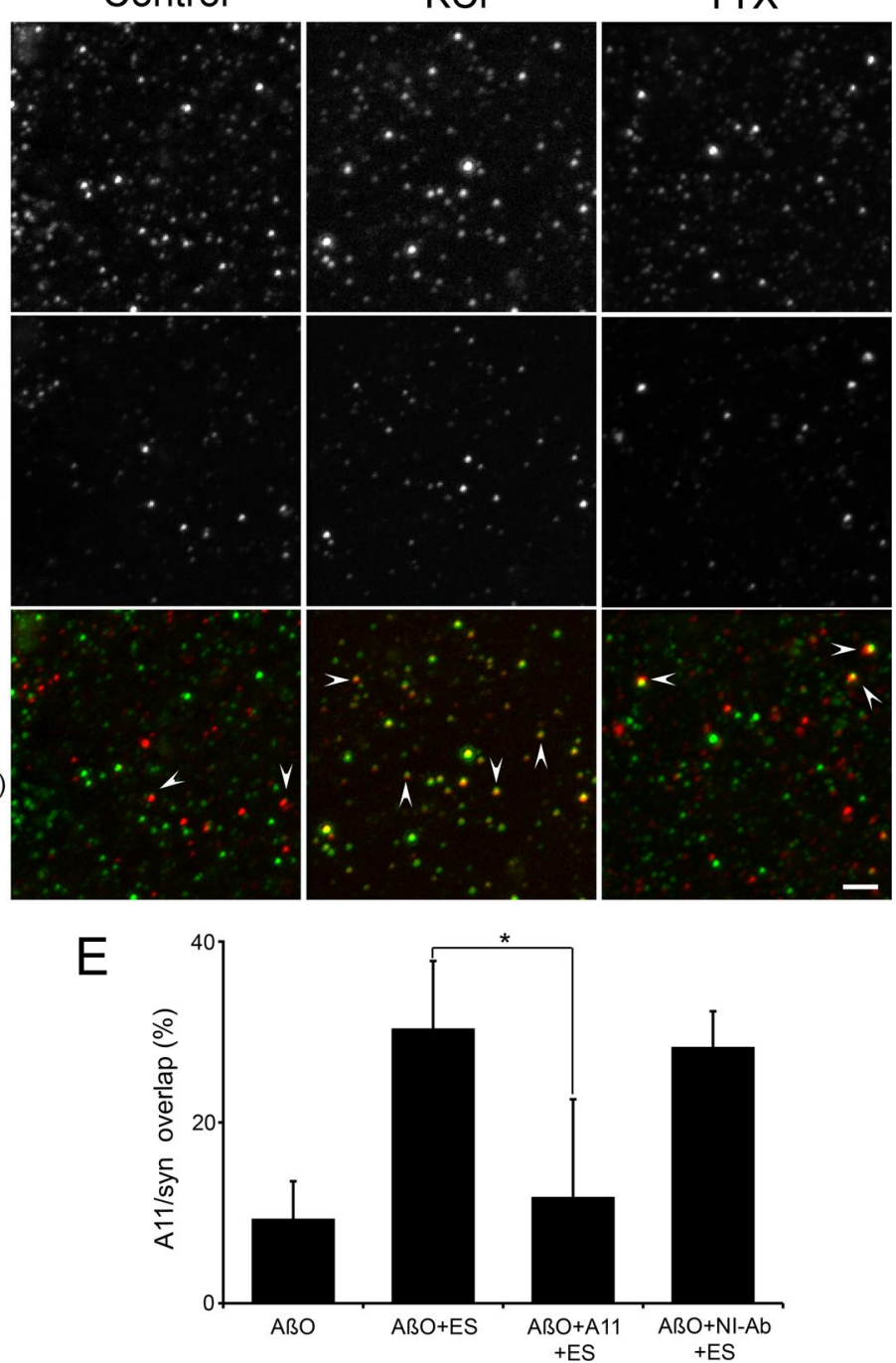

Figure 1. Synaptic activity modulates oligomer targeting to synaptic terminals in rat hippocampal slices. $A$, Schematic representation of the hippocampal formation showing the predetermined areas in CA1, CA3, and the dentate gyrus (DG) where oligomer synaptic localization was quantified. $\boldsymbol{B}$, Double immunofluorescence of A $\beta 0$ (A11; red; 1:2500) and anti-synaptophysin (green; 1:500) showing the puncta-like pattern of immunoreactivity obtained with both antibodies. Arrowheads point to several examples of oligomer/synapse colocalization in merged images. Slices were incubated with $500 \mathrm{~nm} \mathrm{~A} \beta 0$ for $1 \mathrm{~h}$ before fixation. Stimulation with $20 \mathrm{~mm} \mathrm{KCl}$ for $1 \mathrm{~h}$ increased the overlap between $\mathrm{A} \beta 0$ and synaptophysin signals (compare control merge with $\mathrm{KCl}$ merge), whereas preincubation with $2 \mu \mathrm{m}$ TTX for 20 min reduced the oligomer/synaptophysin colocalization (compare KCI merge with TTX merge). Scale bar, $3 \mu \mathrm{m}$. C, Quantification of the frequency of colocalization of oligomers with the presynaptic marker synaptophysin after chemical stimulation. KCl or glutamate significantly increased oligomer synaptic localization. Preincubation with TTX dramatically reduced glutamate-induced synaptic localization of $A \beta 0$. Treatments were performed as described in Materials and Methods. Twenty images at $630 \times$ final magnification were captured in predetermined regions in CA1, CA3, and the dentate gyrus, highlighted in $A$. A total of 60 fields per slice were analyzed. At least three independent slices were analyzed per condition. Oligomer synaptic localization is expressed as the percentage of oligomer puncta colocalized with synaptophysin per field. ${ }^{* *} p<0.01$. D, Blockade of neuronal activity reduces oligomer synaptic accumulation. The histogram shows the frequency of colocalization of $A \beta 0$ with the presynaptic marker synaptophysin. Slices were treated with $A \beta 0, A \beta 0$ plus glutamate, or $A \beta 0$ plus glutamate and subsequent addition of TTX. After a $1 \mathrm{~h}$ incubation with $\mathrm{A} \beta 0$ plus glutamate, TTX was added, and the preparation was incubated for an additional $4 \mathrm{~h}$ before fixation and processing for immunofluorescence and image analysis. Oligomer synaptic localization is expressed as the percentage of oligomer puncta colocalized with synaptophysin per field. Note the significant reduction in oligomer synaptic localization after the addition of TTX to the preparation. ${ }^{*} p<0.05$. $E$, Quantification of the frequency of colocalization of oligomers with the presynaptic marker synaptophysin after electrical stimulation. Extracellular field potentials were recorded in the CA1 or CA3 regions by stimulating the Schaffer collateral or mossy fiber pathways (see Materials and Methods for technical details). Oligomeric synaptic localization increased significantly after electrical stimulation (ES). This increase was prevented by the addition of oligomers and antibody A11 to the slices, but not by the addition of oligomers and a nonimmune lg (NI-Ab). Oligomer synaptic localization is expressed as the percentage of oligomer puncta colocalized with synaptophysin per field. ${ }^{*} p<0.05$. Error bars indicate the mean \pm SEM. syn, Synaptophysin; Glu, glutamate.

Thus, we hypothesized that a local increase in the concentration of zinc as a result of synaptic activity may attract and promote additional aggregation of $\mathrm{A} \beta \mathrm{O}$ at the cleft. To test this hypothesis, we used the zinc-binding $8 \mathrm{OH}$-quinoline clioquinol, which has been shown to decrease $A \beta$ deposits and improve cognitive deficits in AD animal models (Cherny et al., 2001). Clioquinol does not interact directly with $\mathrm{A} \beta$ but binds selectively to the $\mathrm{A} \beta$ metal ion complex and dissociates the metal ion from $\mathrm{A} \beta$
(Cherny et al., 2001). In hippocampal slices coincubated with 500 nм $\mathrm{A} \beta \mathrm{O}$ and $1 \mu \mathrm{m}$ clioquinol for $1 \mathrm{~h}$, the basal level of $\mathrm{A} \beta \mathrm{O}$ synaptic localization decreased from $14.09 \pm 4.18 \%$ to $8.12 \pm$ $1.96 \%$ (Fig. $2 \mathrm{~A}$ ). During stimulation with $\mathrm{KCl}$ or glutamate, clioquinol markedly decreased the percentage of oligomer synaptic localization (KCl, $63.4 \pm 6.62 \%$; $\mathrm{KCl}$ plus clioquinol, $26.46 \pm$ $8.64 \%$; glutamate, $62.4 \pm 6.07 \%$; glutamate plus clioquinol, $22.27 \pm 5.05 \%$ ) (Fig. $2 A$ ). Thus, activity-dependent release of 


\section{A}

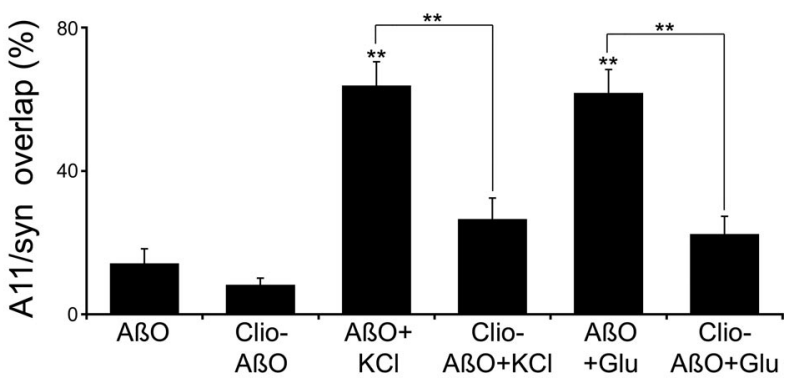

$\mathrm{B}$

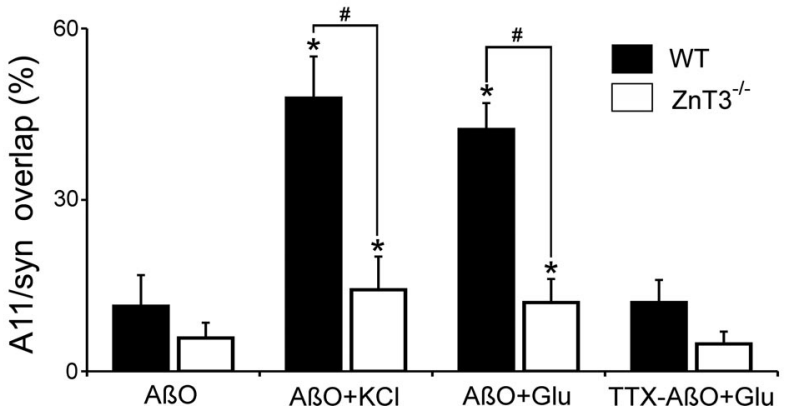

Figure 2. Oligomer synaptic localization is prevented by clioquinol and is reduced in $\mathrm{ZnT}^{-1-}$ brain slices. The frequency of oligomer synaptic localization was assessed as the percentage of overlap between $\mathrm{A} \beta 0$ and synaptophysin signals. $\boldsymbol{A}$, Preincubation with clioquinol resulted in a marked reduction in oligomer synaptic localization after $\mathrm{KCl}$ or glutamate stimulation. $\boldsymbol{B}$, Oligomer synaptic localization was clearly increased in WT mice after $\mathrm{KCl}$ or glutamate stimulation. In contrast, oligomer synaptic accumulation after stimulation remained close to basal levels in slices derived from $\mathrm{ZnT}^{-1-}$ mice. Error bars indicate the mean \pm SEM. ${ }^{*} p<0.05$; ${ }^{* *} p<0.01$; significantly different, ${ }^{\#} p<0.05$. syn, Synaptophysin; Clio, clioquinol; Glu, glutamate.

metal ions at the synaptic cleft may facilitate $\mathrm{A} \beta \mathrm{O}$ synaptic accumulation, and chelation of metal ions significantly reduced oligomeric load at synapses.

To further explore the involvement of synaptic zinc in this process, we used brain slices derived from zinc transporter 3 (ZnT3) knock-out mice. ZnT3 is responsible for the shuttling of zinc into synaptic vesicles. Knocking out the $Z n T 3$ gene results in complete disappearance of zinc in synaptic vesicles throughout the brain without affecting other nonvesicular pools of zinc (Cole et al., 1999). Similar to rat slices, WT mouse hippocampal slices incubated with $500 \mathrm{~nm} \mathrm{~A} \beta \mathrm{O}$ for $1 \mathrm{~h}$ under basal conditions showed a small percentage of synaptic localization. Stimulation with $\mathrm{KCl}$ or glutamate resulted in a marked elevation in $\mathrm{A} \beta \mathrm{O}$ synaptic localization, which was suppressed by coincubation with TTX (Fig. 2B). In contrast, A $\beta O$ synaptic localization was dramatically reduced in $\mathrm{ZnT}^{-1-}$ brain slices after $\mathrm{KCl}$ or glutamate stimulation (Fig. 2 B). This result indicates that release of vesicular zinc from synaptic terminals during neurotransmission is critical for $\mathrm{A} \beta \mathrm{O}$ synaptic localization.

\section{Increased synaptic activity facilitates oligomer formation at} synaptic sites

Because activity-dependent modulation of $\mathrm{A} \beta$ secretion takes place at synaptic terminals (Kamenetz et al., 2003; Cirrito et al., 2005) and metal ions released during synaptic activity enhance A $\beta$ aggregation and oligomer formation (Curtain et al., 2001), we next examined whether synaptic activity was able to initiate and/or accelerate oligomer formation from monomeric $\mathrm{A} \beta$. Hippocampal slices were incubated with $5 \mu \mathrm{M}$ freshly dissolved monomeric $\mathrm{A} \beta$ for 5,30 , or 60 min under basal conditions, or under pulse stimulation with $20 \mathrm{~mm} \mathrm{KCl}$. Then, the slices were fixed, and oligomer formation and colocalization with synaptophysin

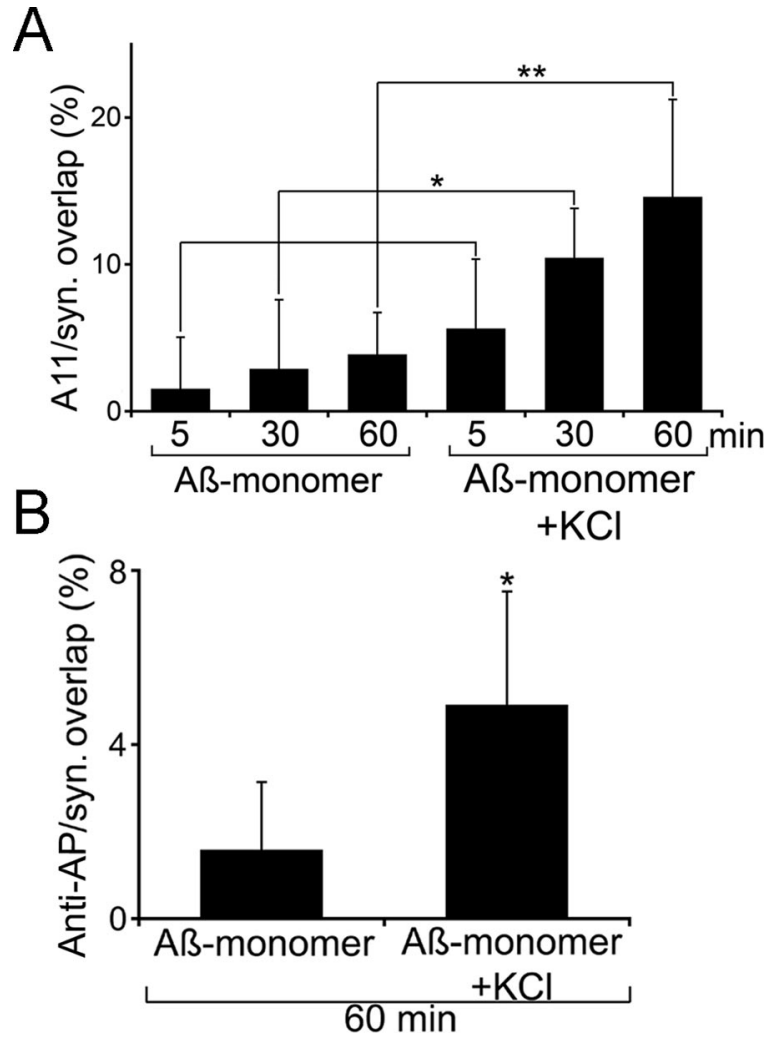

Figure 3. Activity-dependent oligomer formation at synaptic sites. Rat hippocampal slices were incubated with $5 \mu \mathrm{m}$ freshly dissolved monomeric $A \beta$ in the presence or absence of KCl. $\boldsymbol{A}$, A low number of A11-positive structures were observed after 5, 30, or 60 min of incubation in the absence of $\mathrm{KCl}$. The addition of $\mathrm{KCl}$ resulted in a time-dependent increase in the appearance of A11-positive puncta, which colocalized with synaptophysin. $\boldsymbol{B}$, After $60 \mathrm{~min}$, stimulation with $\mathrm{KCl}$ also induced the appearance of anti-annular protofibril (anti-AP)-positive puncta, which colocalized with synaptophysin. Error bars indicate the mean \pm SEM. ${ }^{*} p<0.05 ;{ }^{* *} p<0.01$. syn., Synaptophysin.

were examined. At $5 \mathrm{~min}$, no oligomer-positive puncta were present neither under basal nor stimulated conditions. However, A11-positive puncta colocalized with synaptophysin were observed at $30 \mathrm{~min}(10.03 \pm 3.96 \%)$ and $60 \mathrm{~min}(13.2 \pm 6.19 \%)$ (Fig. 3A), suggesting that synaptic activity enhanced oligomer formation from monomeric A $\beta$. Furthermore, nearly all A11positive puncta colocalized with synaptophysin, strongly suggesting that oligomer formation was indeed taking place at synaptic sites (data not shown). We also analyzed oligomer formation using a conformation-dependent antibody that specifically recognizes annular protofibrils but not mature amyloid fibrils or spherical oligomers (Kayed and Glabe, 2006). It reacts with annular protofibrils regardless of their sequence, indicating the existence of a common epitope that is distinct from the epitopes specific to amyloid fibrils or oligomers recognized by A11. Antiannular protofibril immunoreactivity exhibited rare, scattered puncta-like immunoreactivity on rat slices after the addition of $\mathrm{A} \beta$ monomer under basal conditions, but stimulation with $\mathrm{KCl}$ significantly increased both the frequency and synaptic localization of the immunofluorescence (Fig. 3B), suggesting that synaptic activity enhances the assembly of higher-order oligomer structures at synaptic terminals.

Oligomers remain on the cell surface and are not internalized into endocytic vesicles

$\mathrm{A} \beta \mathrm{O}$ synaptic accumulation may be related to the high endocytic activity that occurs during vesicle recycling, leading to rapid oli- 


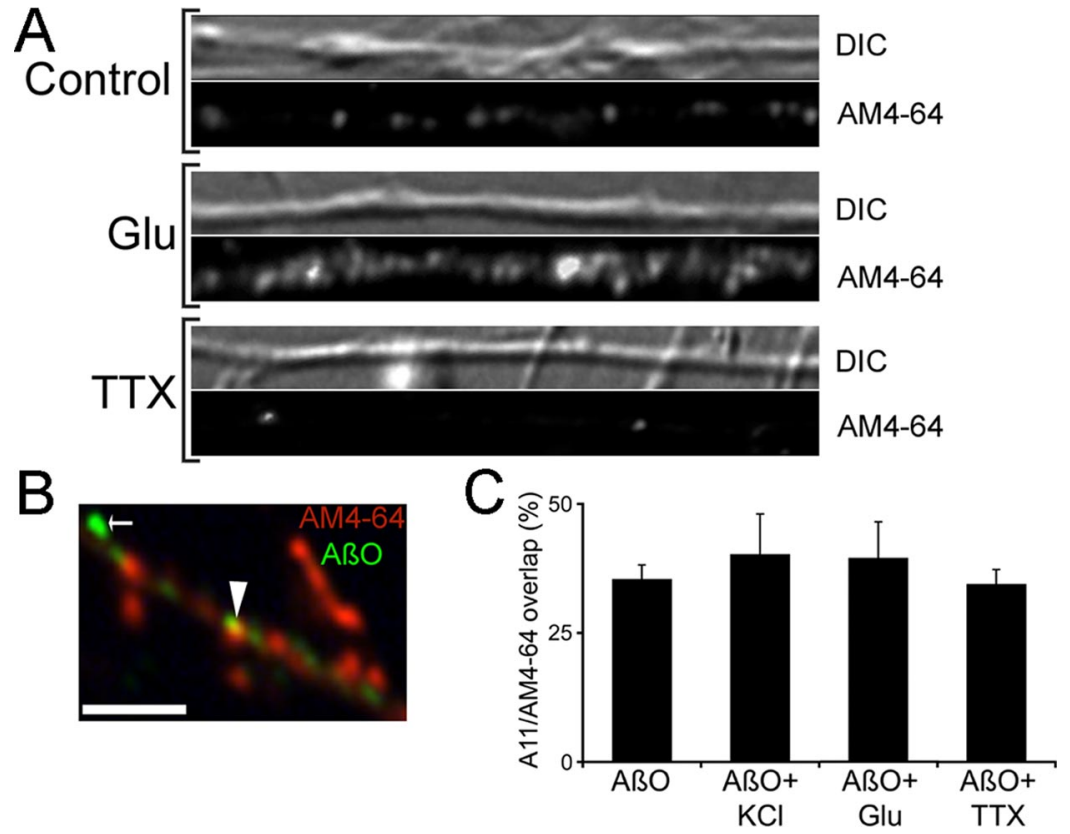

Figure 4. Oligomers are not endocytosed in synaptic vesicles. Vesicular uptake studies were performed in HCNs using the fluorescent cationic styryl fixable dye AM4-64, which is taken up during vesicle recycling. $A$, Differential interference contrast (DIC) and fluorescent (AM4-64) images of neuronal processes under control conditions and after glutamate or TTX treatment. Stimulation with glutamate significantly increased the number of AM4-64-filled vesicles in neuronal processes. Treatment with TTX blocked synaptic activity, vesicle recycling, and the incorporation of AM4-64 into vesicles. $\boldsymbol{B}$, After stimulation and AM4-64 vesicle loading, the cultures were fixed and labeled with anti-oligomer A11 antibody. The image shows oligomer immunoreactivity (green) and AM4-64-positive vesicles (red). The arrowhead points to a site of oligomer/AM4-64 colocalization. Most oligomer puncta were spatially segregated from AM4-64-positive vesicles (arrow). Scale bar: $\boldsymbol{A}, \boldsymbol{B}, 2 \mu \mathrm{m}$. C, Quantification of oligomer colocalization with recycled vesicles. Modulation of synaptic activity with $\mathrm{KCl}$, glutamate, or TTX had no effect on the frequency of oligomer colocalization with AM4-64. Error bars indicate the mean \pm SEM. Glu, glutamate.

gomer internalization. To test this possibility, we tracked endocytic vesicles that pick up the fixable dye AM4-64 during vesicle recycling. After $21 \mathrm{~d}$ in culture, HCNs establish a high number of synapses (Deshpande et al., 2006, 2008), allowing the tracking of individual AM4-64-positive endocytic vesicles, which are visualized as fine puncta-like structures accumulating along neuronal processes. The number of AM4-64-positive puncta increased significantly after the addition of $\mathrm{KCl}$ or glutamate for $5 \mathrm{~min}$, consistent with enhanced vesicle recycling after stimulation. In contrast, AM4-64-positive puncta decreased dramatically with TTX preincubation (Fig. 4A). When $\mathrm{A} \beta \mathrm{O}$ and AM4-64 were added simultaneously (Fig. $4 B, C$ ), the frequency of colocalization of A11 immunofluorescence with AM4-64 did not change after stimulation with $\mathrm{KCl}$ or glutamate despite the higher density of AM4-64 puncta, nor did it change after inhibition with TTX, indicating that oligomers are not localized in AM4-64-containing vesicles (Fig. $4 C$ ). Furthermore, most $\mathrm{A} \beta \mathrm{O}$ still remained at the cell surface as determined by quantitative immunofluorescence of permeabilized and nonpermeabilized cultures fixed after a $30 \mathrm{~min}$ incubation with $\mathrm{A} \beta \mathrm{O}$ (data not shown). Together, these experiments suggest that $\mathrm{A} \beta \mathrm{O}$ accumulation at synaptic sites is not attributable to increased internalization during vesicle recycling.

\section{NMDA but not AMPA receptor activity enhances A $\beta O$ synaptic targeting}

To identify the receptor(s) that mediates oligomer synaptic targeting, we modulated NMDA and AMPA activities with the NMDA receptor antagonists APV and memantine and the AMPA receptor antagonist CNQX. Hippocampal slices were subjected to a 10 min preincubation with $10 \mu \mathrm{M} \mathrm{APV}, 10 \mu \mathrm{M}$ memantine, or
$10 \mu \mathrm{M}$ CNQX before the simultaneous addition of glutamate and A $\beta O$. APV significantly decreased the synaptic localization of oligomers from $65.81 \pm 15.36 \%$ to $22.12 \pm 14.30 \%$ (Fig. 5A). A comparable result was obtained with memantine (from $65.81 \pm 15.36 \%$ to $20.82 \pm 9.76 \%$ ) In contrast, blockade of AMPA receptors with $C N Q X$ did not affect $A \beta O$ synaptic localization (Fig. 5A). Similar results were obtained using ADDL preparations (data not shown). Thus, NMDA but not AMPA receptor activity appears to regulate $A \beta O$ synaptic targeting. Consistent with these results, stimulation of hippocampal slices with glutamate led to a marked increase in the colocalization of $\mathrm{A} \beta \mathrm{O}$ with the NR2B subunit of the NMDA receptor from $19.89 \pm 4.82 \%$ (basal) to $47.11 \pm 10.72 \%$ (stimulated) (Fig. 5B), in agreement with recent data pointing to an association of oligomers with NMDA receptors (Lacor et al., 2007). The involvement of NR2B subunits in oligomer synaptic targeting was also tested using ifenprodil, a noncompetitive antagonist of NMDA receptors highly selective for the NR2B subunit (PerinDureau et al., 2002). A 10 min preincubation with $5 \mu \mathrm{M}$ ifenprodil before the addition of glutamate and $\mathrm{A} \beta \mathrm{O}$ significantly decreased oligomer synaptic localization from $65.81 \pm 15.36 \%$ to $37.76 \pm 8.91 \%$

(Fig. 5A), implicating NR2B activity in oligomer targeting to excitatory synapses.

\section{$\mathrm{A} \beta \mathrm{O}$ s colocalize with synaptic markers in $\mathrm{AD}$ brains}

To evaluate the presence of $\mathrm{A} \beta \mathrm{O}$ s at synaptic terminals in the human brain, we analyzed brain sections obtained from 10 control subjects with no clinical or pathological history of AD and 15 $\mathrm{AD}$ patients. Immunodetection of synapses and synaptic density were established using the colocalization of presynaptic and postsynaptic markers synaptophysin and PSD-95 in the hippocampal formation and frontal and entorhinal cortices. The colocalization of synaptophysin with PSD-95 ranged from 90 to 95\% in all cases (Fig. 6A). Thus, synaptophysin was selected as the synaptic marker for colocalization studies with A11 and additionally with the conformation-specific antibodies NU-2, NU-4, and M69, which specifically recognize synthetic ADDLs as well as ADDLs purified from AD brains (Lambert et al., 2007). All three anti-ADDL antibodies tested yielded a similar pattern of staining (data not shown). Under our experimental conditions, NU-2 was deemed the most suitable for oligomeric labeling in human brain sections. Puncta-like structures immunoreactive for A11 and NU-2 were observed in eight AD and two control cases. Among oligomer-positive cases, there was marked variation in the percentage of colocalization of A11 or NU-2 immunoreactivity with synaptophysin. Some cases exhibited higher levels of oligomeric accumulation but a low degree of oligomer synaptic localization (e.g., case 7-03) (Fig. 6B), whereas other cases showed lower oligomer density but a high degree of oligomer synaptic localization (e.g., case 24-01) (Fig. 6B). Higher magnification and image reconstruction illustrate the tight arrangement between oligomer and synaptic marker signals, very 
similar to the profiles obtained from images reconstructed after PSD-95/synaptophysin double immunostaining (Fig. 6C; and supplemental movie, available at www.jneurosci.org as supplemental material). There was significant variation in the extent of oligomer deposition among positive cases, as well as regional variations in individual cases. Oligomer density (percentage of A11-positive areas per field) varied from $2.49 \pm 1.11$ to $12.32 \pm 2.63 \%$ (Fig. 6D). In general, the hippocampal formation was the area with the highest oligomer density. There was no clear association between total oligomer deposition (oligomer density) (Fig. 6D) and oligomer synaptic localization (Fig 6E). Similarly, there was no correlation between total oligomer deposition levels and synaptic loss (Fig. 6, compare D,F). However, reduced synaptic density was consistently observed in cases of high oligomer synaptic localization (Fig. 6, compare E, F), suggesting an association between oligomer synaptic localization and synaptic loss in $\mathrm{AD}$ brains. Similar results were obtained with NU-2 antibody. Neither A11 nor NU-2 exhibited significant immunoreactivity associated with neuritic plaques or tangles (data not shown). Image analysis revealed that NU-2 labeled smaller-size puncta than A11, whereas anti-annular protofibrils antibody reacted with less abundant but significantly larger structures than NU-2 or A11 (Fig. 7), implying remarkable heterogeneity in the size of endogenous oligomer assemblies in the AD brain. Most oligomers localized at synapses overlapped with NR2B immunoreactivity (Fig. 8). Thus, in the AD brain, excitatory synapses containing the NR2B subunit of the NMDA receptor appear to be principal sites of oligomer accumulation.

\section{Activity-dependent increase in synaptic localization of native oligomers from $\mathrm{AD}$ brains}

To assess the activity of native oligomers, high-speed supernatants from AD brain homogenates containing A11-positive oligomers were separated by PAGE under native or denaturing conditions (see Materials and Methods). Western blot analysis with A11 revealed a major band at $75-100 \mathrm{kDa}$, which was not recognized by nonconformation-dependent anti-A $\beta$ antibodies $6 \mathrm{~F} / 3 \mathrm{D}$ (Fig. $9 A$ ) or $6 \mathrm{E} 10$ (data not shown). In contrast, A11 immunoreactivity was abolished after denaturing PAGE, whereas $6 \mathrm{~F} / 3 \mathrm{D}$ recognized two major low molecular weight bands, suggesting that denaturing conditions disrupt the core structure recognized by A11 and promote its dissociation into monomers and/or smaller oligomer species (Fig. 9A). Oligomers extracted from three different $\mathrm{AD}$ brain samples were pooled and used for synaptic localization studies in rat hippocampal slices after electrical stimulation. Native oligomers showed little overlap with synaptic markers under basal conditions. However, a marked increase in synaptic localization was observed after electrical stimulation
(Fig. 9B, $C$ ). Image analysis revealed significant variation in the particle size of native oligomers (Fig. 9D), reminiscent of the size heterogeneity detected by A11 in AD brain sections. Thus, native oligomers extracted from $\mathrm{AD}$ brains can actively bind to synaptic terminals and this binding is modulated by neuronal activity.

\section{Discussion}

To understand the role of oligomeric $\mathrm{A} \beta$ species in $\mathrm{AD}$ pathology, it is critical to elucidate the mechanism(s) by which oligomers are targeted to synaptic terminals. Here, we show that neuronal activity modulates the localization of both synthetic and native $\mathrm{A} \beta \mathrm{O}$ s to synapses in rat hippocampal slices and HCNs. Stimulation of neuronal activity by $\mathrm{KCl}$ or glutamate resulted in dramatic increases in $\mathrm{A} \beta \mathrm{O}$ synaptic localization. A similar result was obtained using mild electrical stimulation. The degree of colocalization of $\mathrm{A} \beta \mathrm{O}$ with synaptophysin in the presence of $\mathrm{KCl}$ or glutamate was comparable, suggesting that excitatory synapses are the main site of $\mathrm{A} \beta \mathrm{O}$ accumulation. TTX, a potent inhibitor of sodium channels, completely blocked the increase in synaptic oligomers after chemical or electrical stimulation, underscoring the role of neuronal activity in $\mathrm{A} \beta \mathrm{O}$ synaptic localization. Copper 


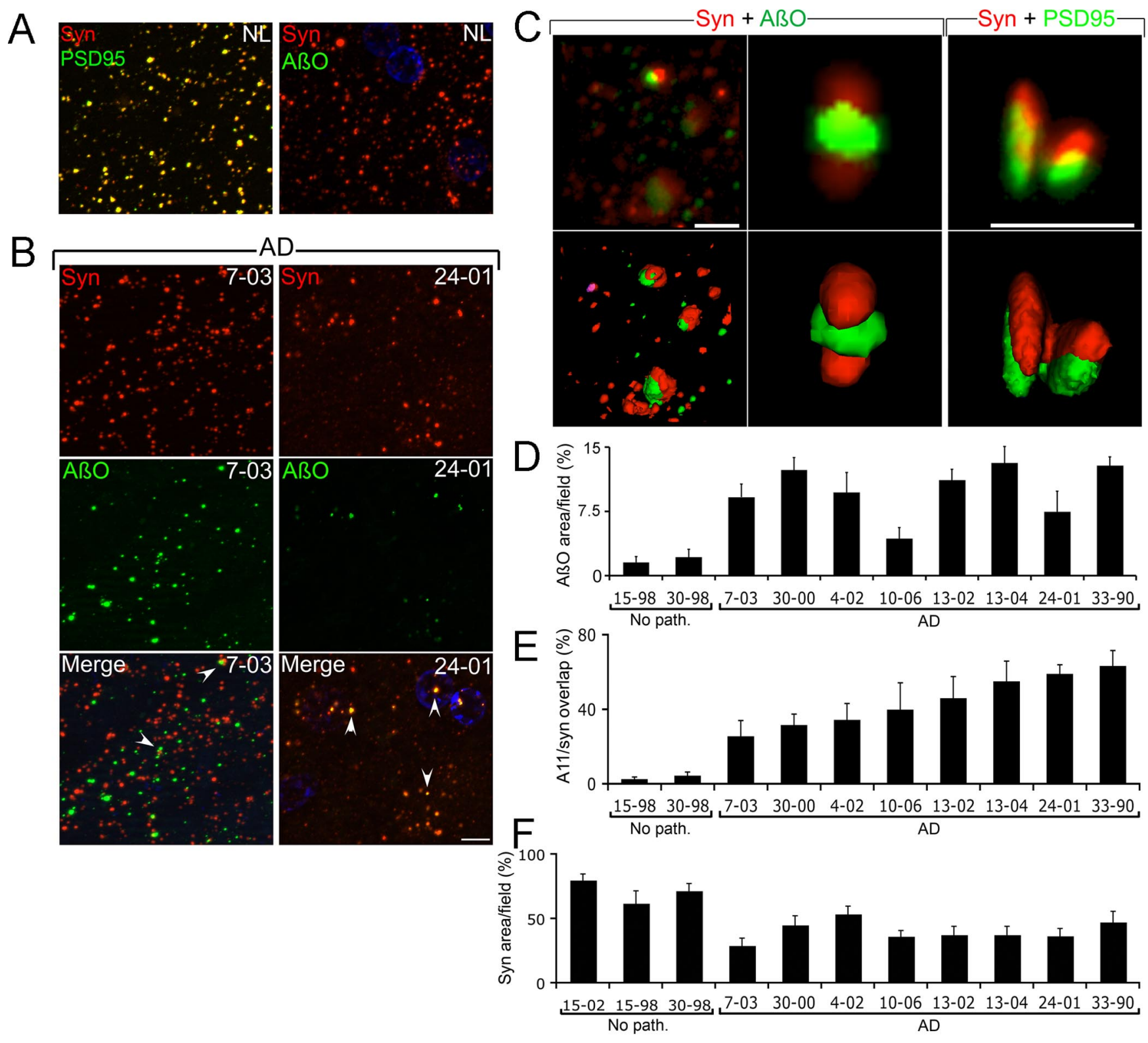

Figure 6. Oligomers colocalize with synaptic markers in AD brains. $A$, Left, Colocalization of anti-synaptophysin (red) and anti-PSD-95 (green) was used to identify synapses in human brain sections. The image shows extensive colocalization of the two signals in a normal (NL) brain. Right, Double immunofluorescence with anti-oligomer and anti-synaptophysin antibodies in a normal brain section. Anti-oligomer immunoreactivity was absent in most non-AD brains analyzed. Scale bar, $5 \mu \mathrm{m}$. B, Double immunofluorescence with anti-oligomer and anti-synaptophysin antibodies in two AD cases (left, 7-03; right, 24-01). Case 7-03 is an example of an abundant oligomeric signal but low synaptic localization, whereas case 24-01 exhibited lower oligomeric signal but high synaptic localization. In both merged panels, arrowheads highlight several examples of oligomer/synaptophysin colocalization. Scale bar, $5 \mu \mathrm{m}$. C, Image analysis and 3D reconstruction illustrating the spatial association between synaptophysin (Syn) and oligomers $(A B 0)$ and between synaptophysin and PSD-95 in an AD brain section (see supplemental movie, available at www.jneurosci.org as supplemental material, for 3D rotating views). Top, Regular merged image. Bottom, "Surface" view after image processing. Scale bar, $2 \mu \mathrm{m}$. D, The bar graph illustrates the extent of oligomer deposition in two control and eight AD cases in which positive anti-oligomer immunoreactivity was detected. Oligomer deposition was expressed as the area occupied by anti-oligomer (A11) immunoreactivity per field. $\boldsymbol{E}$, Histogram illustrating the percentage of oligomer localization at synaptic sites expressed as the overlap between A11 and anti-synaptophysin immunoreactivity. The cases were arranged from lower to higher percentage of colocalization. $\boldsymbol{F}$, The bar graph shows synaptic density expressed as the area occupied by synaptophysin immunofluorescence per field. In $\mathbf{D}-\boldsymbol{F}$, at least 30 fields (630 $\times$ final magnification) were analyzed per section corresponding to frontal cortex, entorhinal cortex, and hippocampal regions (10 fields/region). Error bars indicate the mean \pm SEM. Syn, Synaptophysin; No path., control.

and zinc, which bind $\mathrm{A} \beta$ with high affinity (Bush et al., 1994b; Atwood et al., 2000), are released at synaptic terminals during neurotransmission (Frederickson and Bush, 2001; Frederickson et al., 2005). The zinc- and copper-binding 8-OH-quinoline clioquinol reduced the presence of oligomers at synapses during stimulation, suggesting a role for metal ions in this process. Oligomeric synaptic targeting was markedly reduced in sections from $\mathrm{ZnT}^{-1-}$ mice, which lack synaptic zinc (Cole et al., 1999), indicating that transient elevations in the concentration of zinc at the cleft during neurotransmission may contribute to the recruitment of $\mathrm{A} \beta \mathrm{O}$ to synaptic terminals. Alternatively, postsynaptic copper ions released after glutamate stimulation in an NMDAmediated manner (Schlief et al., 2005, 2006) may also be responsible for $\mathrm{A} \beta$ oligomerization and synaptic accumulation. Thus, the effect of clioquinol in rescuing glutamate-mediated $A \beta$ synaptic targeting may be attributable to the trapping of zinc, copper, or both metal ions after stimulation. In this regard, the clioquinol derivative PBT2 is currently under evaluation as a 
potential treatment for $\mathrm{AD}$ and has shown the ability to rapidly reverse cognition deficits in $\mathrm{AD}$ transgenic mice (Adlard et al., 2008).

Previous studies have suggested that exogenous $\mathrm{A} \beta$ may be internalized via endocytosis (Narita et al., 1997; Hughes et al., 1998; Atwood et al., 2000), raising the possibility that high vesicle turnover at synaptic terminals may also result in oligomer accumulation and/or internalization during vesicle recycling. However, at short incubation times, we did not $\operatorname{detect} \mathrm{A} \beta \mathrm{O}$ internalization in recycled vesicles but a sustained presence of $\mathrm{A} \beta \mathrm{O}$ at the synaptic surface, which peaked between $30 \mathrm{~min}$ to $1 \mathrm{~h}$. Although previous studies suggest that $\mathrm{A} \beta$ is eventually internalized with longer incubation times (Gylys et al., 2003), our data indicate that $\mathrm{A} \beta \mathrm{O}$ accumulation at synaptic sites is not attributable to increased internalization during synaptic vesicle recycling.

Glutamate stimulation resulted in a significant enhancement of oligomer colocalization with NR2B receptor subunits in both rat slices and HCNs, in accord with a recent study demonstrating the association of oligomers with NMDA receptors (Lacor et al., 2007). Pharmacological treatments showed that the NMDA antagonists APV, memantine, and ifenprodil markedly reduced oligomer synaptic targeting, indicating the involvement of excitatory NMDA receptors in this process. Thus, it might be relevant to also investigate the modulation of excitatory neurotransmission as a potential therapeutic strategy to reduce oligomer synaptic accumulation and toxicity.

Once oligomers reach the synaptic terminal, there is evidence for multiple mechanisms involved in $\mathrm{A} \beta \mathrm{O}$-mediated synaptic dysfunction including interaction with NMDA receptors (Fig. 5) (Snyder et al., 2005; Lacor et al., 2007), interaction with other proteins present at synapses such as apolipoprotein E or APP (Lorenzo et al., 2000; Sadowski et al., 2006), or disruption of insulin receptor signaling (Zhao et al., 2008). Oligomers can also compromise synaptic function by altering the permeability of neuronal membranes and disrupting ion homeostasis (Kayed et al., 2004; Glabe and Kayed, 2006). In our previous study, we characterized a stereotyped succession of cellular changes triggered by $\mathrm{A} \beta \mathrm{O}$ s after synaptic localization, which were consistent with the activation of a mitochondrial death pathway (Deshpande et al., 2006). However, lower $\mathrm{A} \beta \mathrm{O}$ concentrations (in the nanomolar range) induced chronic mitochondrial alterations but not neuronal death (Deshpande et al., 2006). In this regard, subtle oligomer-induced mitochondrial deficits may contribute to defective synaptic activity and cognitive impairment during the disease process. Regardless of the cellular mechanism(s) engaged in oligomer toxicity, neuronal activity not only enhanced oligomer targeting but also facilitated oligomer formation at synaptic sites (Fig. 3). Similar to synaptic zinc, $A \beta$ is normally released at presynaptic terminals in an activity-dependent manner
B

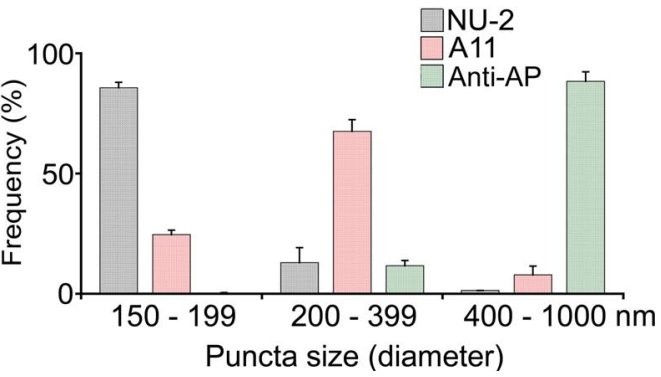

Figure 7. Different conformation-specific antibodies detect oligomeric structures of different size in AD brains. $A$, Doubleimmunofluorescence images illustrating oligomer particles of different size positive for A11, NU-2, and anti-annular protofibril tibodies, respectively (green). White brackets highlight the diameter of some oligomeric particles. The solarization filter in from eight $A D$ brains exhibiting anti-oligomer immunoreactivity were analyzed for object size and frequency. The results are

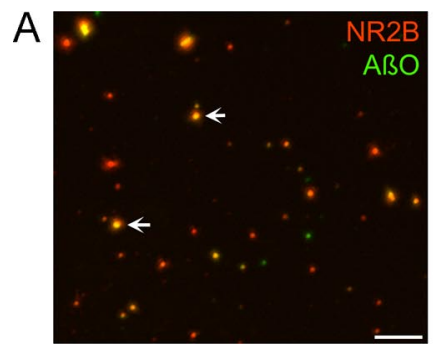

$\mathrm{B}$

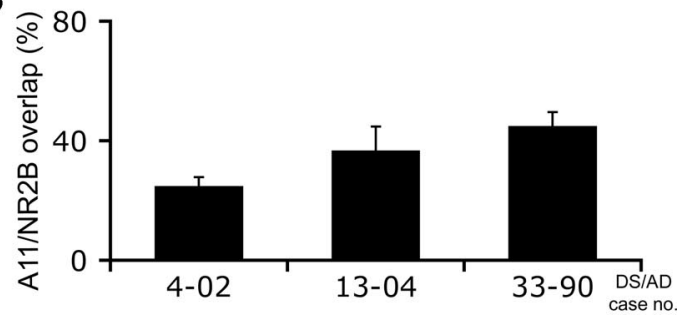

Figure 8. Oligomers colocalize with NR2B in AD brains. $A$, Double immunofluorescence showing anti-oligomer A11 (green) and anti-NR2B (red) staining in the hippocampus of an AD brain. Arrows highlight examples of oligomer/NR2B colocalization. 33-90). Oligomer synaptic localization is expressed as the percentage of oligomeric puncta colocalized with NR2B per field. At least 20 fields were analyzed in the hippocampus and entorhinal cortex in each case. Error bars indicate the mean \pm SEM. DS/AD, Down's syndrome with AD neuropathology.

(Nitsch et al., 1993; Kamenetz et al., 2003; Cirrito et al., 2005), where it induces NMDA receptor-dependent synaptic depression (Kamenetz et al., 2003). Thus, sustained synaptic activity stimulating release and transient increases in both monomeric $A \beta$ and zinc may lead to rapid assembly of oligomer structures at the cleft. This is especially significant in light of recent experiments describing $\mathrm{A} \beta$-induced intermittent neuronal hyperexcitability and nonconvulsive seizure activity in the cortex and hippocampus of hAPP-J20 mice, a mouse model of AD with high A $\beta$ levels (Palop et al., 2007). Neuronal overexcitation may further stimulate $A \beta$ synaptic release and oligomerization at synaptic sites. Furthermore, because there is a higher incidence of seizures in $\mathrm{AD}$ patients (Amatniek et al., 2006), aberrant neuronal activity may stimulate oligomer accumulation at synapses during the disease process, eventually leading to impaired synaptic plasticity and synaptic loss. Alternatively, zinc sequestration in $\mathrm{A} \beta$-zinc complexes may lead to reduced zinc availability at synaptic terminals and the consequent loss of zinc modulatory activity at excitatory synapses (Frederickson et al., 2005). In addition, zinc has been recently characterized as a novel regulator of synaptic plasticity by its ability to transactivate TrkB (tyrosine kinase receptor B) receptors (Huang et al., 2008). Additional studies will be required to establish the relationship between zinc functional alterations at synaptic terminals and cognitive deficits in $\mathrm{AD}$. 

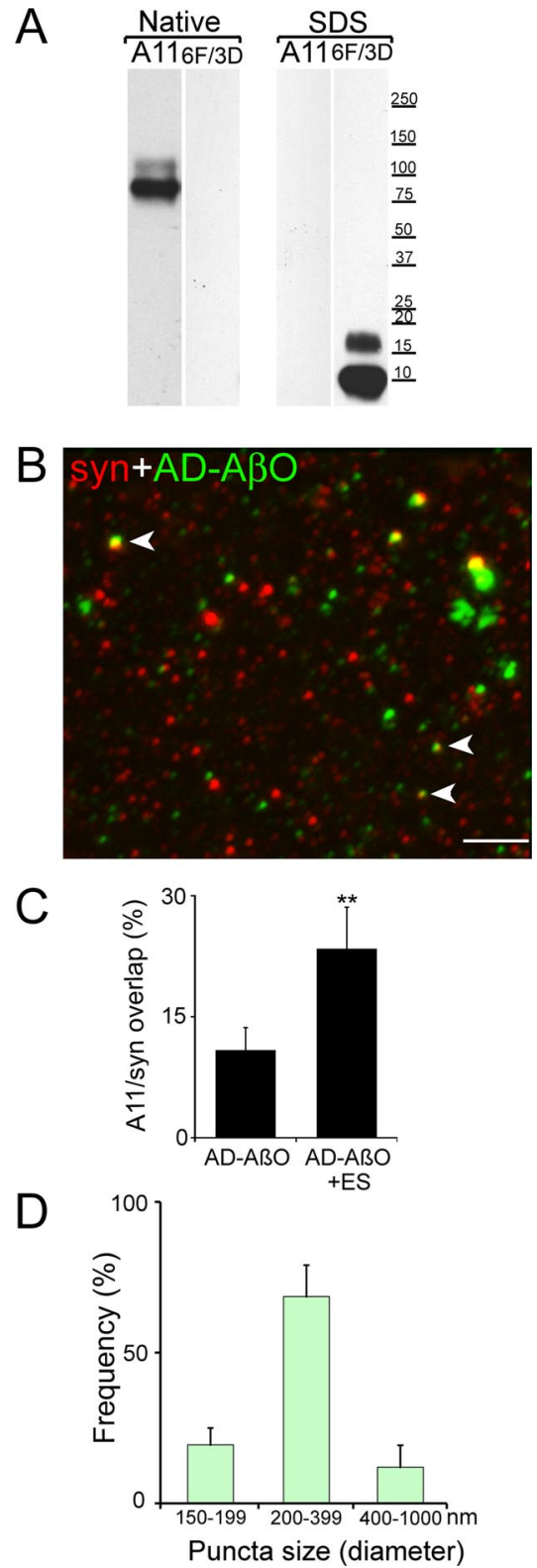

Figure 9. Activity-dependent synaptic localization of native oligomers extracted from AD brains. $A$, Western blot analysis of soluble fractions from AD brain homogenates. Samples extracted from three different AD brain specimens were pooled and separated by PAGE under nondenaturing (native) and denaturing (SDS) conditions. A11-positive bands at $\sim 75-100 \mathrm{kDa}$ can be observed in the material separated under native conditions. These bands are not recognized by the nonconformation-dependent anti- $\mathrm{A} \beta$ antibody $6 \mathrm{~F} / 3 \mathrm{D}$. Under denaturing conditions, A11 staining was negative, and $6 \mathrm{~F} / 3 \mathrm{D}$ recognized two major low molecular weight bands. $B$, Colocalization of native oligomers extracted from AD brain samples stained with A11 (green) and synaptophysin (red) in rat brain slices after electrical stimulation (arrowheads). Scale bar, 5 $\mu \mathrm{m}$. C, The histogram shows the percentage of native oligomer colocalization with synaptophysin under basal conditions (AD-A $\beta 0$ ) and after electrical stimulation (AD-A $\beta 0+E S)$. Error bars indicate the mean \pm SEM. ${ }^{* *} p<0.01$. $\boldsymbol{D}$, Binning histogram based on puncta size of native oligomers extracted from $A D$ brain specimens. The oligomer-containing fraction was added to rat brain slices. After a $1 \mathrm{~h}$ incubation, slices were fixed, and immunofluorescence was performed with A11 antibody. At least 10 microscopic fields corresponding to the hippocampal formation and cortical areas of the slice were analyzed for object size and frequency in three independent slices. The results are expressed as the mean \pm SEM. syn, Synaptophysin.

We detected oligomer immunoreactivity in 8 of $15 \mathrm{AD}$ cases and 2 of 10 control brains examined. Image reconstruction revealed similar overlap of signals between presynaptic and postsynaptic markers and between oligomers and presynaptic markers, indicating synaptic localization of oligomers. The frequency of oligomers at synapses in $\mathrm{AD}$ brains did not correlate with the general extent of oligomer deposition, raising the possibility that other factors (e.g., increased synaptic activity) may favor oligomer synaptic recruitment. In fact, all AD cases showing significant oligomer synaptic localization consistently exhibited reduced synaptic density, suggesting an association between the presence of oligomers at synapses and synaptic loss.

Both the frequency of oligomer deposition and oligomer synaptic localization differed among $\mathrm{AD}$ cases. This could be attributed to a number of factors, including variations in neuronal activity among individuals. Another possibility is that the postmortem interval may affect the number of oligomers present at synapses. For instance, oligomers may be released or drift away from synapses once neuronal activity ceases. In this regard, sustained inhibition with TTX after glutamate stimulation resulted in a marked reduction in the level of oligomers originally localized at synapses, indicating that this phenomenon is at least partially reversible by synaptic silencing (Fig. 1D).

Three different conformation-specific antibodies used to detect endogenous oligomers in human tissue (A11, NU-2, and anti-annular protofibrils) labeled puncta-like structures of different size, consistent with biochemical data describing the presence of heterogeneous oligomer conformations in the AD brain (Gong et al., 2003). In accord with the in vitro results, most endogenous synaptic oligomers also colocalized with NMDA NR2B subunits in $\mathrm{AD}$ brains, pointing to excitatory synapses as major sites of oligomer accumulation. Native oligomers extracted from $\mathrm{AD}$ brains also showed size heterogeneity and the ability to target synapses in an activity-dependent manner in rat brain slices. Additional research will be required to establish whether different oligomer assemblies exhibit a different capacity to bind to synapses and/or to induce synaptic dysfunction.

In summary, our results indicate that synaptic activity plays a fundamental role in oligomer formation and accumulation at excitatory synapses. Neuronal overactivity during the course of the disease may exacerbate $\mathrm{A} \beta$ generation and secretion and, based on this study, oligomer formation and synaptic accumulation. Ongoing experiments are directed to further understand the relationship between neuronal activity and the dynamics of $A \beta O$ assembly, and to establish the time course of oligomer deposition at synaptic terminals during the disease process.

\section{References}

Adlard PA, Cherny RA, Finkelstein DI, Gautier E, Robb E, Cortes M, Volitakis I, Liu X, Smith JP, Perez K, Laughton K, Li QX, Charman SA, Nicolazzo JA, Wilkins S, Deleva K, Lynch T, Kok G, Ritchie CW, Tanzi RE, et al. (2008) Rapid restoration of cognition in Alzheimer's transgenic mice with 8-hydroxy quinoline analogs is associated with decreased interstitial Abeta. Neuron 59:43-55.

Amatniek JC, Hauser WA, DelCastillo-Castaneda C, Jacobs DM, Marder K, Bell K, Albert M, Brandt J, Stern Y (2006) Incidence and predictors of seizures in patients with Alzheimer's disease. Epilepsia 47:867-872.

Atwood CS, Scarpa RC, Huang X, Moir RD, Jones WD, Fairlie DP, Tanzi RE, Bush AI (2000) Characterization of copper interactions with Alzheimer amyloid beta peptides: identification of an attomolar-affinity copper binding site on amyloid beta1-42. J Neurochem 75:1219-1233.

Billings LM, Oddo S, Green KN, McGaugh JL, LaFerla FM (2005) Intraneuronal Abeta causes the onset of early Alzheimer's disease-related cognitive deficits in transgenic mice. Neuron 45:675-688.

Billings LM, Green KN, McGaugh JL, LaFerla FM (2007) Learning decreases A beta ${ }^{*} 56$ and tau pathology and ameliorates behavioral decline in 3xTg-AD mice. J Neurosci 27:751-761.

Bush AI, Pettingell WH Jr, Paradis MD, Tanzi RE (1994a) Modulation of A beta adhesiveness and secretase site cleavage by zinc. J Biol Chem 269:12152-12158. 
Bush AI, Pettingell WH, Multhaup G, d Paradis M, Vonsattel JP, Gusella JF, Beyreuther K, Masters CL, Tanzi RE (1994b) Rapid induction of Alzheimer A beta amyloid formation by zinc. Science 265:1464-1467.

Chang L, Bakhos L, Wang Z, Venton DL, Klein WL (2003) Femtomole immunodetection of synthetic and endogenous amyloid-beta oligomers and its application to Alzheimer's disease drug candidate screening. J Mol Neurosci 20:305-313.

Cherny RA, Atwood CS, Xilinas ME, Gray DN, Jones WD, McLean CA, Barnham KJ, Volitakis I, Fraser FW, Kim Y, Huang X, Goldstein LE, Moir RD, Lim JT, Beyreuther K, Zheng H, Tanzi RE, Masters CL, Bush AI (2001) Treatment with a copper-zinc chelator markedly and rapidly inhibits beta-amyloid accumulation in Alzheimer's disease transgenic mice. Neuron 30:665-676.

Cirrito JR, Yamada KA, Finn MB, Sloviter RS, Bales KR, May PC, Schoepp DD, Paul SM, Mennerick S, Holtzman DM (2005) Synaptic activity regulates interstitial fluid amyloid-beta levels in vivo. Neuron 48:913-922.

Cleary JP, Walsh DM, Hofmeister JJ, Shankar GM, Kuskowski MA, Selkoe DJ, Ashe KH (2005) Natural oligomers of the amyloid-beta protein specifically disrupt cognitive function. Nat Neurosci 8:79-84.

Cole TB, Wenzel HJ, Kafer KE, Schwartzkroin PA, Palmiter RD (1999) Elimination of zinc from synaptic vesicles in the intact mouse brain by disruption of the ZnT3 gene. Proc Natl Acad Sci U S A 96:1716-1721.

Curtain CC, Ali F, Volitakis I, Cherny RA, Norton RS, Beyreuther K, Barrow CJ, Masters CL, Bush AI, Barnham KJ (2001) Alzheimer's disease amyloid-beta binds copper and zinc to generate an allosterically ordered membrane-penetrating structure containing superoxide dismutase-like subunits. J Biol Chem 276:20466-20473.

Deshpande A, Mina E, Glabe C, Busciglio J (2006) Different conformations of amyloid $\beta$ induce neurotoxicity by distinct mechanisms in human cortical neurons. J Neurosci 26:6011-6018.

Deshpande A, Win KM, Busciglio J (2008) Tau isoform expression and regulation in human cortical neurons. FASEB J 22:2357-2367.

Frederickson CJ, Bush AI (2001) Synaptically released zinc: physiological functions and pathological effects. Biometals 14:353-366.

Frederickson CJ, Koh JY, Bush AI (2005) The neurobiology of zinc in health and disease. Nat Rev Neurosci 6:449-462.

Georganopoulou DG, Chang L, Nam JM, Thaxton CS, Mufson EJ, Klein WL, Mirkin CA (2005) Nanoparticle-based detection in cerebral spinal fluid of a soluble pathogenic biomarker for Alzheimer's disease. Proc Natl Acad Sci U S A 102:2273-2276.

Glabe CG (2004) Conformation-dependent antibodies target diseases of protein misfolding. Trends Biochem Sci 29:542-547.

Glabe CG, Kayed R (2006) Common structure and toxic function of amyloid oligomers implies a common mechanism of pathogenesis. Neurology 66:S74-S78.

Goedert M, Spillantini MG (2006) A century of Alzheimer's disease. Science 314:777-781.

Gong Y, Chang L, Viola KL, Lacor PN, Lambert MP, Finch CE, Krafft GA, Klein WL (2003) Alzheimer's disease-affected brain: presence of oligomeric A beta ligands (ADDLs) suggests a molecular basis for reversible memory loss. Proc Natl Acad Sci U S A 100:10417-10422.

Gylys KH, Fein JA, Tan AM, Cole GM (2003) Apolipoprotein E enhances uptake of soluble but not aggregated amyloid-beta protein into synaptic terminals. J Neurochem 84:1442-1451.

Haass C, Selkoe DJ (2007) Soluble protein oligomers in neurodegeneration: lessons from the Alzheimer's amyloid beta-peptide. Nat Rev Mol Cell Biol 8:101-112.

Head E, Lott IT, Cribbs DH, Cotman CW, Rohn TT (2002) Beta-amyloid deposition and neurofibrillary tangle association with caspase activation in Down syndrome. Neurosci Lett 330:99-103.

Holscher C, Gengler S, Gault VA, Harriott P, Mallot HA (2007) Soluble beta-amyloid[25-35] reversibly impairs hippocampal synaptic plasticity and spatial learning. Eur J Pharmacol 561:85-90.

Huang YZ, Pan E, Xiong ZQ, McNamara JO (2008) Zinc-mediated transactivation of TrkB potentiates the hippocampal mossy fiber-CA3 pyramid synapse. Neuron 57:546-558.

Hughes SR, Khorkova O, Goyal S, Knaeblein J, Heroux J, Riedel NG, Sahasrabudhe S (1998) Alpha2-macroglobulin associates with beta-amyloid peptide and prevents fibril formation. Proc Natl Acad Sci U S A 95:3275-3280.

Kamenetz F, Tomita T, Hsieh H, Seabrook G, Borchelt D, Iwatsubo T, Sisodia
S, Malinow R (2003) APP processing and synaptic function. Neuron 37:925-937.

Kayed R, Glabe CG (2006) Conformation-dependent anti-amyloid oligomer antibodies. Methods Enzymol 413:326-344.

Kayed R, Head E, Thompson JL, McIntire TM, Milton SC, Cotman CW, Glabe CG (2003) Common structure of soluble amyloid oligomers implies common mechanism of pathogenesis. Science 300:486-489.

Kayed R, Sokolov Y, Edmonds B, McIntire TM, Milton SC, Hall JE, Glabe CG (2004) Permeabilization of lipid bilayers is a common conformationdependent activity of soluble amyloid oligomers in protein misfolding diseases. J Biol Chem 279:46363-46366.

Kayed R, Head E, Sarsoza F, Saing T, Cotman CW, Necula M, Margol L, Wu J, Breydo L, Thompson JL, Rasool S, Gurlo T, Butler P, Glabe CG (2007) Fibril specific, conformation dependent antibodies recognize a generic epitope common to amyloid fibrils and fibrillar oligomers that is absent in prefibrillar oligomers. Mol Neurodegener 2:18.

Kuo YM, Emmerling MR, Vigo-Pelfrey C, Kasunic TC, Kirkpatrick JB, Murdoch GH, Ball MJ, Roher AE (1996) Water-soluble Abeta (N-40, N-42) oligomers in normal and Alzheimer disease brains. J Biol Chem 271:4077-4081.

Lacor PN, Buniel MC, Chang L, Fernandez SJ, Gong Y, Viola KL, Lambert MP, Velasco PT, Bigio EH, Finch CE, Krafft GA, Klein WL (2004) Synaptic targeting by Alzheimer's-related amyloid $\beta$ oligomers. J Neurosci 24:10191-10200.

Lacor PN, Buniel MC, Furlow PW, Clemente AS, Velasco PT, Wood M, Viola KL, Klein WL (2007) Abeta oligomer-induced aberrations in synapse composition, shape, and density provide a molecular basis for loss of connectivity in Alzheimer's disease. J Neurosci 27:796-807.

Lambert MP, Barlow AK, Chromy BA, Edwards C, Freed R, Liosatos M, Morgan TE, Rozovsky I, Trommer B, Viola KL, Wals P, Zhang C, Finch CE, Krafft GA, Klein WL (1998) Diffusible, nonfibrillar ligands derived from Abeta1-42 are potent central nervous system neurotoxins. Proc Natl Acad Sci U S A 95:6448-6453.

Lambert MP, Velasco PT, Chang L, Viola KL, Fernandez S, Lacor PN, Khuon D, Gong Y, Bigio EH, Shaw P, De Felice FG, Krafft GA, Klein WL (2007) Monoclonal antibodies that target pathological assemblies of Abeta. J Neurochem 100:23-35.

Lesne S, Koh MT, Kotilinek L, Kayed R, Glabe CG, Yang A, Gallagher M, Ashe $\mathrm{KH}$ (2006) A specific amyloid-beta protein assembly in the brain impairs memory. Nature 440:352-357.

Lorenzo A, Yuan M, Zhang Z, Paganetti PA, Sturchler-Pierrat C, Staufenbiel M, Mautino J, Vigo FS, Sommer B, Yankner BA (2000) Amyloid beta interacts with the amyloid precursor protein: a potential toxic mechanism in Alzheimer's disease. Nat Neurosci 3:460-464.

Lue LF, Kuo YM, Roher AE, Brachova L, Shen Y, Sue L, Beach T, Kurth JH, Rydel RE, Rogers J (1999) Soluble amyloid beta peptide concentration as a predictor of synaptic change in Alzheimer's disease. Am J Pathol 155:853-862.

Mathie A, Sutton GL, Clarke CE, Veale EL (2006) Zinc and copper: pharmacological probes and endogenous modulators of neuronal excitability. Pharmacol Ther 111:567-583.

McLean CA, Cherny RA, Fraser FW, Fuller SJ, Smith MJ, Beyreuther K, Bush AI, Masters CL (1999) Soluble pool of Abeta amyloid as a determinant of severity of neurodegeneration in Alzheimer's disease. Ann Neurol 46:860-866.

Mocchegiani E, Bertoni-Freddari C, Marcellini F, Malavolta M (2005) Brain, aging and neurodegeneration: role of zinc ion availability. Prog Neurobiol 75:367-390.

Moolman DL, Vitolo OV, Vonsattel JP, Shelanski ML (2004) Dendrite and dendritic spine alterations in Alzheimer models. J Neurocytol 33:377-387.

Mucke L, Masliah E, Yu GQ, Mallory M, Rockenstein EM, Tatsuno G, Hu K, Kholodenko D, Johnson-Wood K, McConlogue L (2000) High-level neuronal expression of Abeta 1-42 in wild-type human amyloid protein precursor transgenic mice: synaptotoxicity without plaque formation. J Neurosci 20:4050-4058.

Narita M, Holtzman DM, Schwartz AL, Bu G (1997) Alpha2-macroglobulin complexes with and mediates the endocytosis of beta-amyloid peptide via cell surface low-density lipoprotein receptor-related protein. J Neurochem 69:1904-1911.

Naslund J, Haroutunian V, Mohs R, Davis KL, Davies P, Greengard P, Bux- 
baum JD (2000) Correlation between elevated levels of amyloid betapeptide in the brain and cognitive decline. JAMA 283:1571-1577.

Necula M, Kayed R, Milton S, Glabe CG (2007) Small molecule inhibitors of aggregation indicate that amyloid beta oligomerization and fibrillization pathways are independent and distinct. J Biol Chem 282:10311-10324.

Nguyen HD, Hall CK (2004) Molecular dynamics simulations of spontaneous fibril formation by random-coil peptides. Proc Natl Acad Sci U S A 101:16180-16185.

Nitsch RM, Farber SA, Growdon JH, Wurtman RJ (1993) Release of amyloid beta-protein precursor derivatives by electrical depolarization of rat hippocampal slices. Proc Natl Acad Sci U S A 90:5191-5193.

Oddo S, Caccamo A, Tran L, Lambert MP, Glabe CG, Klein WL, LaFerla FM (2006) Temporal profile of amyloid-beta (Abeta) oligomerization in an in vivo model of Alzheimer disease. A link between Abeta and tau pathology. J Biol Chem 281:1599-1604.

Palop JJ, Chin J, Roberson ED, Wang J, Thwin MT, Bien-Ly N, Yoo J, Ho KO, Yu GQ, Kreitzer A, Finkbeiner S, Noebels JL, Mucke L (2007) Aberrant excitatory neuronal activity and compensatory remodeling of inhibitory hippocampal circuits in mouse models of Alzheimer's disease. Neuron 55:697-711.

Pelsman A, Hoyo-Vadillo C, Gudasheva TA, Seredenin SB, Ostrovskaya RU, Busciglio J (2003) GVS-111 prevents oxidative damage and apoptosis in normal and Down's syndrome human cortical neurons. Int J Dev Neurosci 21:117-124.

Perin-Dureau F, Rachline J, Neyton J, Paoletti P (2002) Mapping the binding site of the neuroprotectant ifenprodil on NMDA receptors. J Neurosci 22:5955-5965.

Roselli F, Tirard M, Lu J, Hutzler P, Lamberti P, Livrea P, Morabito M, Almeida OF (2005) Soluble $\beta$-amyloid1-40 induces NMDA-dependent degradation of postsynaptic density-95 at glutamatergic synapses. J Neurosci 25:11061-11070.

Sadowski MJ, Pankiewicz J, Scholtzova H, Mehta PD, Prelli F, Quartermain D, Wisniewski T (2006) Blocking the apolipoprotein E/amyloid-beta interaction as a potential therapeutic approach for Alzheimer's disease. Proc Natl Acad Sci U S A 103:18787-18792.
Schlief L, West T, Craig AM, Holtzman DM, Gitlin JD (2006) Role of the Menkes copper-transporting ATPase in NMDA receptor-mediated neuronal toxicity. Proc Natl Acad Sci U S A 103:14919-14924.

Schlief ML, Craig AM, Gitlin JD (2005) NMDA receptor activation mediates copper homeostasis in hippocampal neurons. J Neurosci 25:239-246.

Selkoe DJ (1991) The molecular pathology of Alzheimer's disease. Neuron 6:487-498.

Shankar GM, Bloodgood BL, Townsend M, Walsh DM, Selkoe DJ, Sabatini BL (2007) Natural oligomers of the Alzheimer amyloid- $\beta$ protein induce reversible synapse loss by modulating an NMDA-type glutamate receptor-dependent signaling pathway. J Neurosci 27:2866-2875.

Snyder EM, Nong Y, Almeida CG, Paul S, Moran T, Choi EY, Nairn AC, Salter MW, Lombroso PJ, Gouras GK, Greengard P (2005) Regulation of NMDA receptor trafficking by amyloid-beta. Nat Neurosci 8:1051-1058.

Spires TL, Meyer-Luehmann M, Stern EA, McLean PJ, Skoch J, Nguyen PT, Bacskai BJ, Hyman BT (2005) Dendritic spine abnormalities in amyloid precursor protein transgenic mice demonstrated by gene transfer and intravital multiphoton microscopy. J Neurosci 25:7278-7287.

Townsend M, Shankar GM, Mehta T, Walsh DM, Selkoe DJ (2006) Effects of secreted oligomers of amyloid beta-protein on hippocampal synaptic plasticity: a potent role for trimers. J Physiol 572:477-492.

Trojanowski JQ, Lee VM (2002) The role of tau in Alzheimer's disease. Med Clin North Am 86:615-627.

Walsh DM, Klyubin I, Fadeeva JV, Cullen WK, Anwyl R, Wolfe MS, Rowan MJ, Selkoe DJ (2002) Naturally secreted oligomers of amyloid beta protein potently inhibit hippocampal long-term potentiation in vivo. Nature 416:535-539.

Wang HW, Pasternak JF, Kuo H, Ristic H, Lambert MP, Chromy B, Viola KL, Klein WL, Stine WB, Krafft GA, Trommer BL (2002) Soluble oligomers of beta amyloid (1-42) inhibit long-term potentiation but not long-term depression in rat dentate gyrus. Brain Res 924:133-140.

Zhao WQ, De Felice FG, Fernandez S, Chen H, Lambert MP, Quon MJ, Krafft GA, Klein WL (2008) Amyloid beta oligomers induce impairment of neuronal insulin receptors. FASEB J 22:246-260. 